\author{
Military Technical College \\ Kobry El-Kobbah, \\ Cairo, Egypt.
}

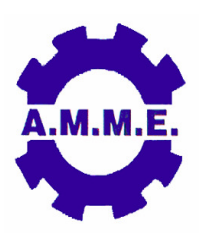

\title{
BALLISTIC PERFORMANCE OF A PROJECTILE WITH A DEVELOPED BOATTAIL
}

\author{
E. El-Awwad*, A. Z. Ibrahim*, A. M. El-Sebae* and A. M. Riad*
}

\begin{abstract}
A computational study using Reynolds-Averaged Navier-Stokes (RANS) equations has been carried out to investigate air flow past projectiles provided with nonaxisymmetric boattail at transonic and supersonic speeds. The non-axisymmetric boattail is formed by cutting the conventional boattail with three flat surfaces having inclination angle of ten degrees. The present study aims to discuss the effect of the existence of these flat surfaces on the air flow characteristics compared to typical projectile having the same base area. One of the study main concerns is the drag and it impact on the projectile trajectory. The present study shows that the existence of flat surfaces on the new unconventional projectile boattail is a reason of weakening the shock wave formed on the boattail. The wake behind the unconventional projectile base is smaller than that of the conventional model. Moreover, the unconventional projectile has a lower pitching moment than the typical projectile at angle of attack of three degrees.
\end{abstract}

\section{KEY WORDS}

Aerodynamics, CFD, projectiles, non-axisymmetric boattail, triangular boattails, drag reduction.

\footnotetext{
* Egyptian Armed Forces
} 


\section{NOMENCLATURE}

$\begin{array}{ll}\mathrm{C}_{D} & \text { total drag coefficient } \\ \mathrm{C}_{\mathrm{Db}} & \text { base drag coefficient } \\ \mathrm{C}_{\mathrm{Ma}} & \text { pitching moment coefficient } \\ \mathrm{D} & \text { projectile caliber } \\ \mathrm{g} & \text { gravitational acceleration } \\ \mathrm{L}_{T} & \text { projectile total length } \\ \mathrm{M} & \text { Mach number } \\ \mathrm{N} & \text { number of cells } \\ \mathrm{N}_{G} & \text { number of cells for used grid } \\ \mathrm{P}_{0} & \text { total pressure } \\ \mathrm{q} & \text { projectile mass } \\ \mathrm{R} & \text { air resistance force } \\ \mathrm{Re} & \text { Reynolds number } \\ \mathrm{S} & \text { projectile reference area } \\ \mathrm{T}_{0} & \text { total temperature } \\ \mathrm{V}_{\mathrm{x}} & \text { velocity component in } \mathrm{x} \text { direction } \\ \mathrm{V}_{\mathrm{y}} & \text { velocity component in y direction } \\ \mathrm{X}_{\mathrm{S}} & \text { distance of rear stagnation point from base } \\ \mathrm{y}^{+} & \text {wall } \mathrm{y}^{+} \text {function } \\ \beta & \text { boattail angle } \\ \theta_{0} & \text { firing angle } \\ \rho & \text { density } \\ \tau_{\mathrm{w}} & \text { wall shear stress }\end{array}$

\section{INTRODUCTION}

Ballistic performance of artillery projectiles has been an important issue for the ammunition designers since their main concern was to extend the range and to improve the stability during flight on the trajectory in air. Drag reduction has been a direct means of increasing the range of artillery projectiles which often have a blunt base. The corresponding base drag has been recognized as a major part of the total drag. Thus, base drag reduction is an effective approach to get better ballistic performance [1]. Conventional axisymmetric conical boattailing is the simplest effective method to reduce base drag by decreasing the base area and extent of flow expansion at the base corner [2]. At transonic speeds, boattailing has two unfavorable effects on projectile. The first effect is the generation of large Magnus forces and moments which adversely affect the gyroscopic and dynamic stability of the projectile [3]. The second effect is the formation of normal shock wave over the boattail which increases the wave drag especially with large boattail angles $\left(\beta>5^{\circ}\right)$ [4].

In order to minimize the penalties of axisymmetric boattailing without a trade-off for base drag reduction, non-axisymmetric boattails have been proposed instead [3]. The shapes of these boattials are square, triangular and cruciform. They are formed by cutting the projectile cylindrical part with planes making an inclination with the projectile axis. Wind tunnel tests have been performed on projectiles of calibers 2.25 and 4.25 inches provided with non-axisymmetric boattails. At transonic and 
supersonic speeds, it has been found that the triangular boattail achieved the lowest drag, good pitching moment, and low Magnus moment resulting in better projectile stability during its flight.

Kayester and Sturek performed inviscid flow computational study on nonaxisymmetric projectiles [5]. The objective of their study was to determine to what extent the existing computational capability can be used for determining the flow field over non-axisymmetric shapes. They predicted the surface pressure, normal force and pitching moment coefficients using three-dimensional inviscid flow field computations past a non-spinning non-conical boattail. Some computational works using different techniques were carried out in order to investigate the steady inviscid aerodynamic behavior of projectiles having various axisymmetric and nonaxisymmetric boattail shapes [6-8].

A computational aerodynamic study [6-8], using a thin-layer parabolized NavierStokes computational technique, was made for an initial design configuration intended for $25 \mathrm{~mm}$ sub-caliber training round supplied with a triangular boattail. The purpose of such a design is to limit the range of the round through aerodynamic destabilization. Another computational study [9] using parabolized Navier-Stokes computational technique showed that the ersonic speeds with non-axisymmetric boattails are small at hypersonic speeds and beneficial effects on the aerodynamic coefficients obtained at transonic and suplow angles of attack.

Therefore, it can be noted that the triangular base has remarked aerodynamic benefits when it is provided to artillery projectiles flying at transonic and supersonic speeds. However, ammunition designers confronted the problem of increasing the unconventional boattail length resulting in less loading space of the propellant in the cartridge case as shown in Fig. 1. Thus, a lower muzzle velocity is obtained due to decreasing of the propellant mass. This disadvantage is the motivation towards a new developed boattail shape discussed in the current study. The new developed boattail is designed such that its base area is of the same area as that one for the conical boattail of seven degrees beveling angle. Therefore, the developed boattail is formed by cutting a conventional conical end of five degrees beveling angle with three flat surfaces of inclination angle of ten degrees which are interspersed by the remaining curvy surfaces of the conical boattail. Hereafter, a computational study to assess the ballistic performance of the developed projectile compared with a conventional projectile is carried out. In addition, a trajectory model is used to estimate the projectile range.

\section{COMPUTATIONAL WORK}

\section{CFD Model}

The computational investigation in this study was carried out by applying ReynoldsAveraged Navier-Stokes (RANS) equations in time independent form using the computational facilities of the commercial code ANSYS Fluent 13. The implicit density base scheme was used to solve the system of differential equations. The second-order upwind Green-Gauss node based scheme was used in discretizing the spatial dependent properties in RANS equations. Spalart-Allmaras turbulent model 
[10] was used in this study. Fig. 2 illustrates the relative dimensions of the used projectile models in terms of the caliber $D=30 \mathrm{~mm}$.

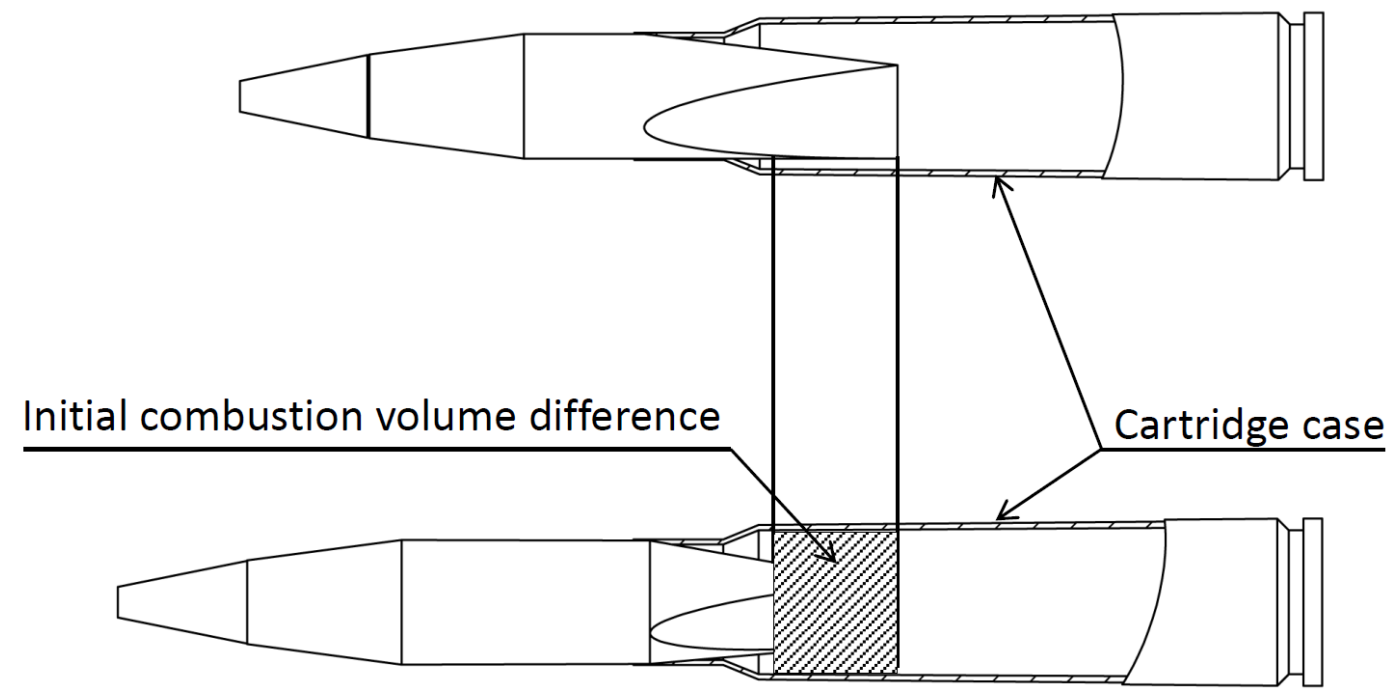

Fig. 1. Change of initial combustion volume.

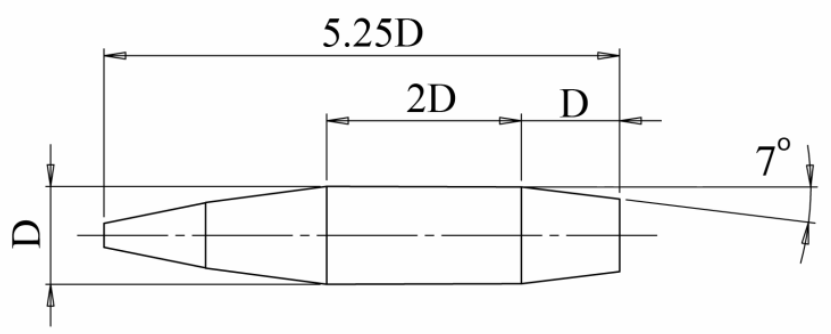

(a) Projectile provided with conventional conical boattail.

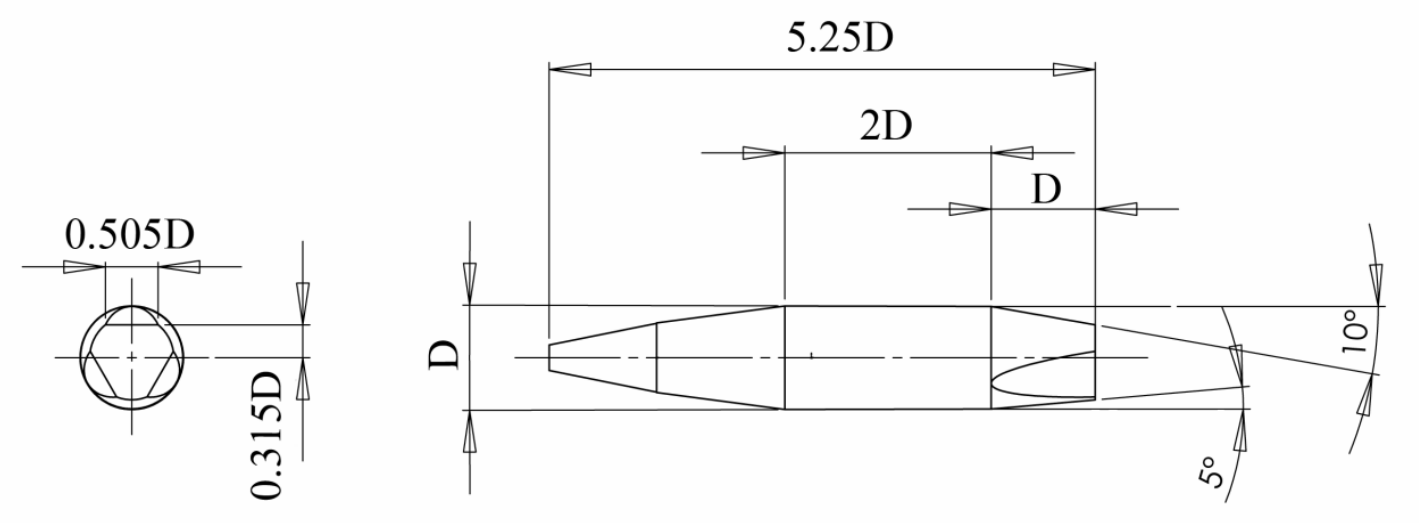

(b) Projectile provided with the unconventional developed boattail.

Fig. 2. Relative dimensions of the projectile models. 


\section{Grid Generation}

The grid sensitivity study was carried out using the two dimensional (2-D) axisymmetric flow simulations over the conventional projectile at Mach number equals to 0.96 at zero incidence. A two dimensional structured quadrilateral O-grid was generated. As shown in Fig. 3, meshing half of the domain is enough since the projectile is a symmetrical body of revolution. The computational domain was divided into six sectors. The division was carried out in order to enhance grid quality and to get proper clustering of the cells in the expected positions of large gradients of flow properties. Five structured 2-D grids have been generated using Gambit 2.4, to obtain the grid of independent solution. The coarsest grid consists of 23000 cells and the finest one consists of 41600 cells. Fig. 4 illustrates the change of total drag coefficient with grid size normalized by the used grid size, $\mathrm{N}_{\mathrm{G}}$. The grid of 36000 cells has been chosen in this study since increasing the grid size makes insignificant change of the total drag coefficient.

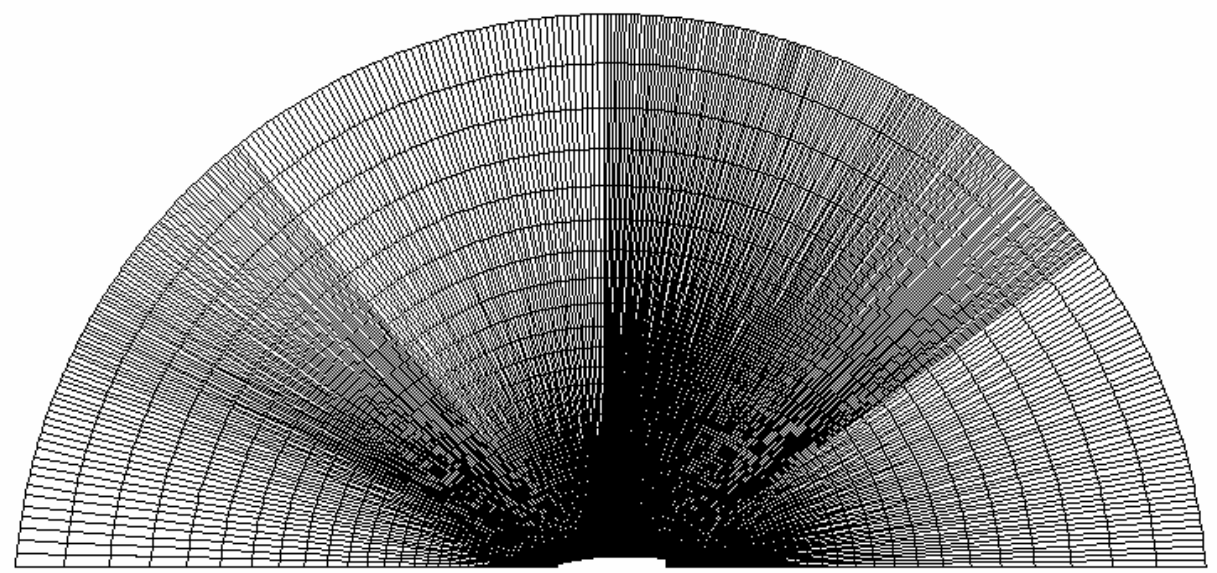

Fig. 3. The structured 2-D mesh.

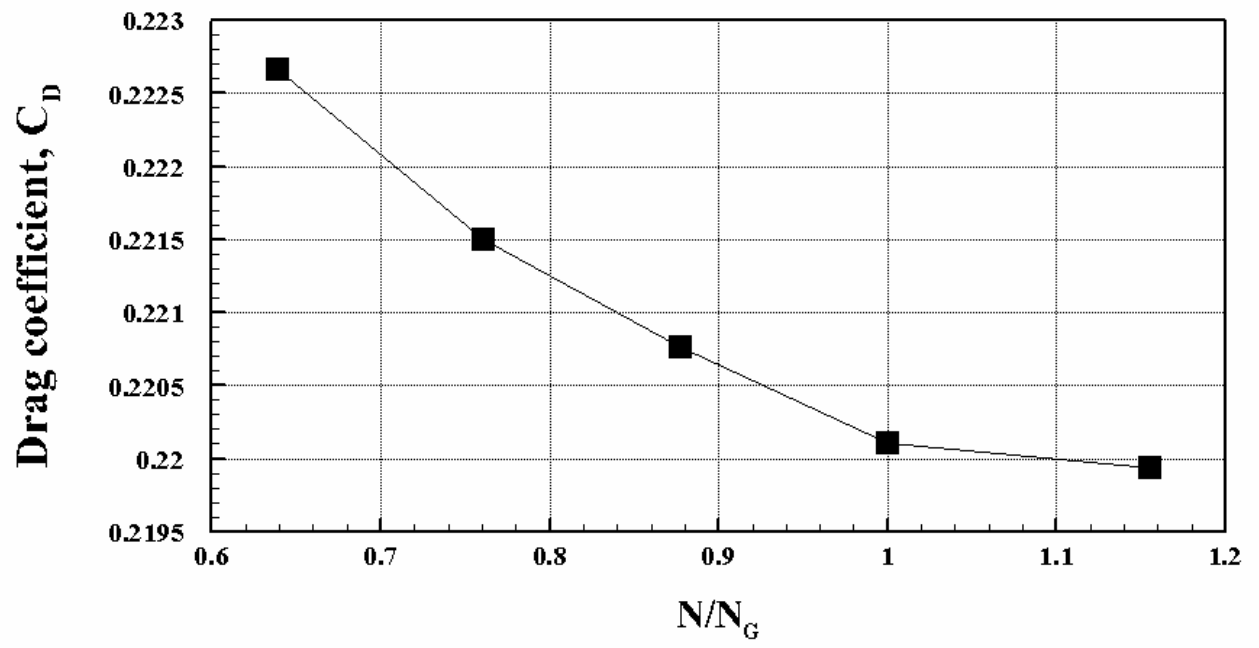

Fig. 4. Variation of the total drag coefficient for the tested grids at $M=0.96$. 
The three dimensional (3-D) grid of the conventional model was generated by rotating the chosen $2-\mathrm{D}$ grid around the projectile axis by $180^{\circ}$ since it is an axisymmetric body of revolution. The final 3-D grid size is 1274400 cells. The pressure far field boundary was taken at a distance of five times the projectile length apart from its walls in all directions. The domain was divided into eighteen sub-volumes in order to increase the capability of enhancing the grid quality. The height of the cells adjacent to the wall is $4 \times 10^{-3} \mathrm{~mm}$ in order to get the value of the wall function $\mathrm{y}^{+}<5$. The nodes along the laterals were stretched towards the far field with a ratio of 1.1.

For the unconventional model, the 3-D half domain structured grid was built to get a grid size of 1918000 cells as shown in Fig. 5. In order to achieve enhanced mesh quality the domain was divided into twenty sub-volumes. The same strategies were followed when treating the pressure far field, the height of the cells adjacent to the walls, the value of the wall function $\mathrm{y}^{+}$, and the expansion ratio along the laterals.

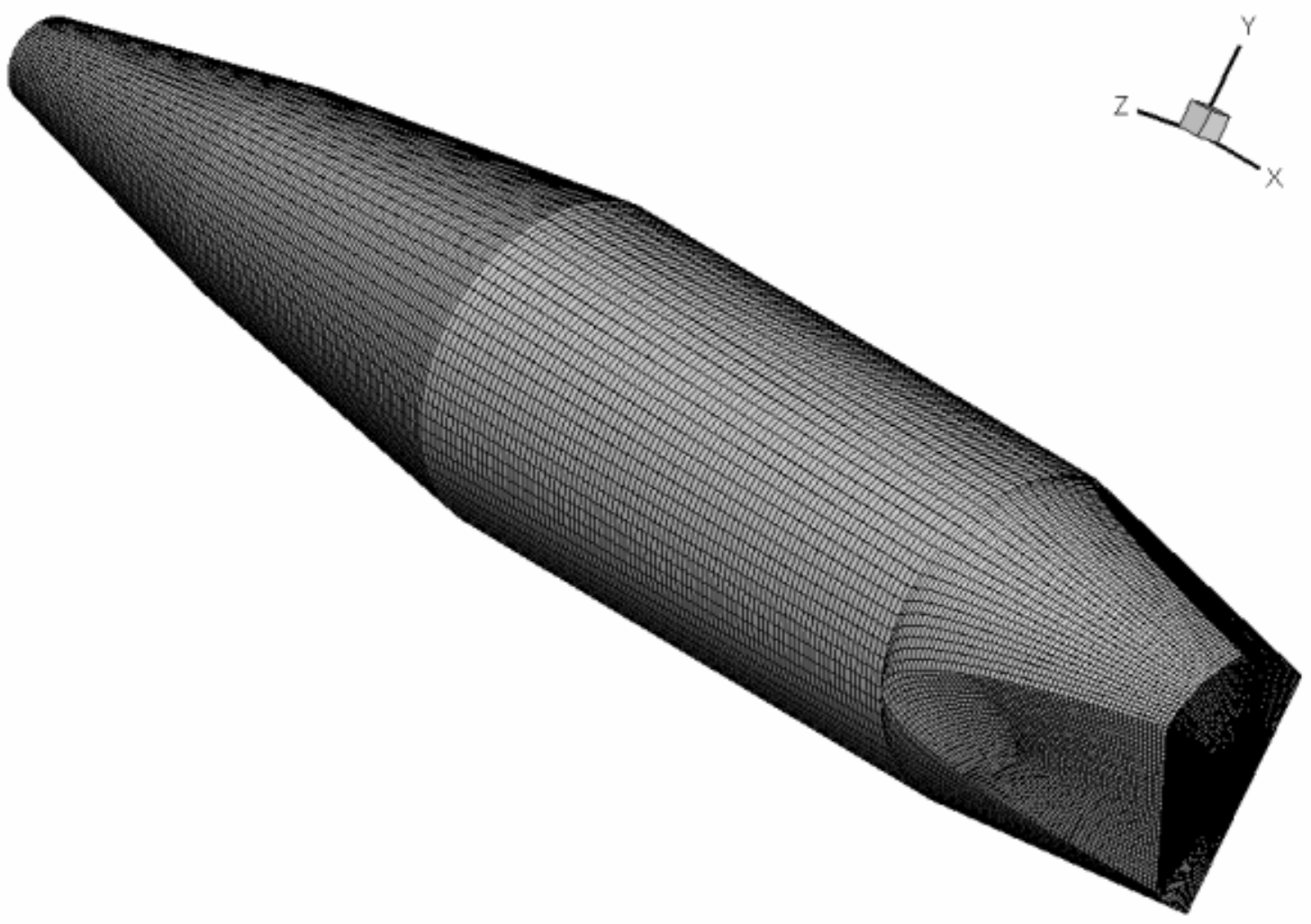

Fig. 5. Three dimensional grids of the unconventional projectile.

\section{Boundary Conditions}

The free stream conditions were defined at far field boundaries as follows: i) total pressure $P_{0}=101325 \mathrm{~Pa}$, ii) total temperature $T_{0}=300^{\circ} \mathrm{K}$, and iii) Mach number ranges from 0.92 to 2.7. The adiabatic no-slip condition was considered on both conventional and nonconventional projectile walls. 


\section{Trajectory Model}

A 2-D point mass model was used to calculate the trajectory parameters assuming that the air resistance force is a collinear with projectile axis as shown in Fig. 6.

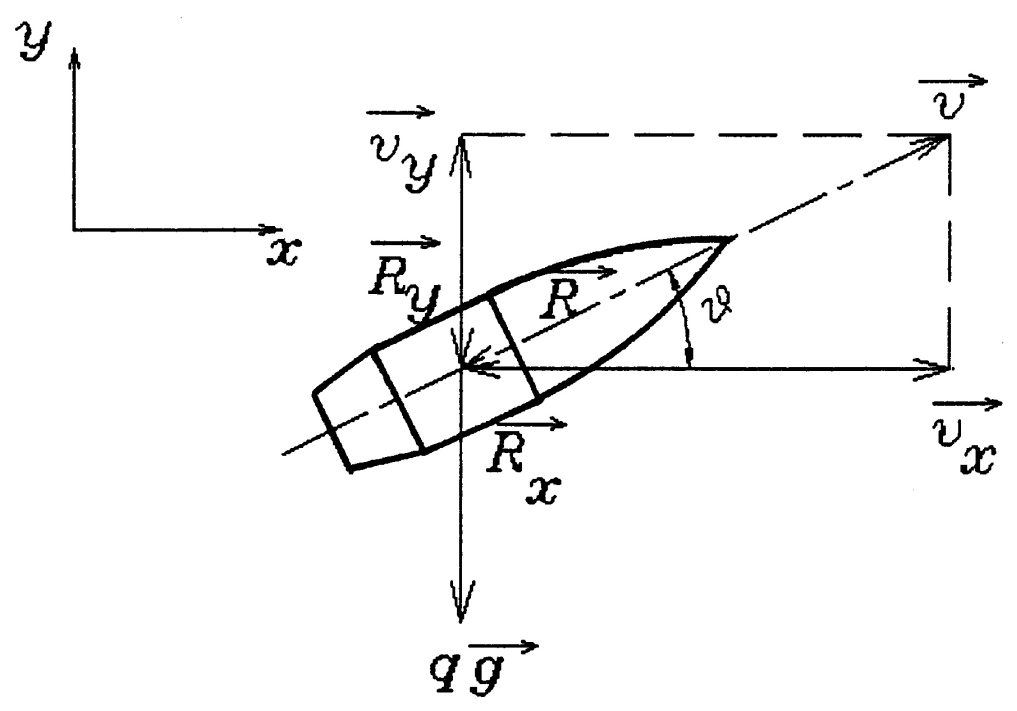

Fig. 6. Air resistance components acting on the projectile during flight.

This figure illustrates the forces acting on atypical artillery projectile during flight. Applying Newton's second law, the projectile equations of motion in the $x$ and $y$ directions will be:

$$
\begin{gathered}
q \frac{d v_{x}}{d t}=-R \cos \epsilon, \\
q \frac{d v_{y}}{d t}=-R \sin \theta-q g,
\end{gathered}
$$

where $v_{x}$, and $v_{y}$, are the components of projectile velocity in both $x$ and $y$ directions, respectively, $q$ is the projectile mass and $g$ is the gravitational acceleration. The air resistance force is given by the following equation:

$$
R=\frac{1}{2} \rho_{\infty} v^{2} S C_{D}(M, R e)
$$

The upstream air density $\rho \infty$ changes with the projectile altitude according to the following equations:

$$
\begin{array}{cc}
\rho_{\mathrm{sc}}=1.225\left(1-0.0065 \frac{y}{T_{o}}\right)^{4.256} & (0 \leq \mathrm{y} \leq 11000 \mathrm{~m}) \\
\rho_{\text {so }}=\rho_{11000} e^{1.57(11000-y) 10^{-4}} & (\mathrm{y}>11000 \mathrm{~m})
\end{array}
$$

where $y$ is the projectile height, $T_{0}$ is the air temperature at sea level, and $\rho_{11000}$ is 
the air density at $11000 \mathrm{~m}$ height. The differential equations of the projectile velocity in both $\mathrm{x}$ and $\mathrm{y}$ directions will be:

$$
\begin{aligned}
& v_{x}=\frac{d x}{d t} \\
& v_{y}=\frac{d y}{d t}
\end{aligned}
$$

To solve equations $1,2,6$, and $7, C_{D}(M)$ is input from the results of CFD simulation. Consequently, Mach number must be determined as follows:

$$
\mathrm{M}=\frac{v}{\sqrt{\gamma R T}}
$$

The following equation relates air temperature to projectile altitude:

$$
\begin{array}{cc}
\mathrm{T}=\mathrm{T}_{0}-0.0065 \mathrm{y}[\mathrm{K}] & (0 \leq \mathrm{y} \leq 11000 \mathrm{~m}) \\
\mathrm{T}=217[\mathrm{~K}] & (\mathrm{y}>11000 \mathrm{~m})
\end{array}
$$

Thus, the system of the differential equations $1,2,6$, and 7 can be solved numerically. A flow chart including the main steps for calculating the projectile trajectory parameters can be seen in Fig. A1.

\section{RESULTS AND DISCUSSIONS}

In this work, the used modeling parameters is similar to the numerical simulation of the triangular and conical boattails [11], which was validated with the experimental work carried out by Anders Platou [3].

Numerical simulations were carried out at angles of attack of $0.0^{\circ}, 3.0^{\circ}$ and $-3.0^{\circ}$ at Mach number ranges from 0.92 to 2.7. The solution was initialized from the conditions at the far field boundary. The total drag coefficient was monitored as criterion of convergence as well as the residuals to reach the order of magnitude of minus three.

Figure 7 shows the difference of total drag coefficient - of both the two current projectiles at zero incidences - with Mach number. At low transonic speeds; the drag acting on the unconventional projectile is lower than its counterpart value of the conventional one. But at high transonic/ supersonic speeds, the drag acting on the conventional projectile is lower.

The wall shear stresses at the boattail surface having maximum inclination angle for both models (ten degrees and seven degrees for unconventional and conventional projectiles respectively) at Mach numbers 0.96, 0.98, 2.5 and 2.7 are shown in Fig. 8 , respectively. The condition of flow separation is that the velocity gradient 


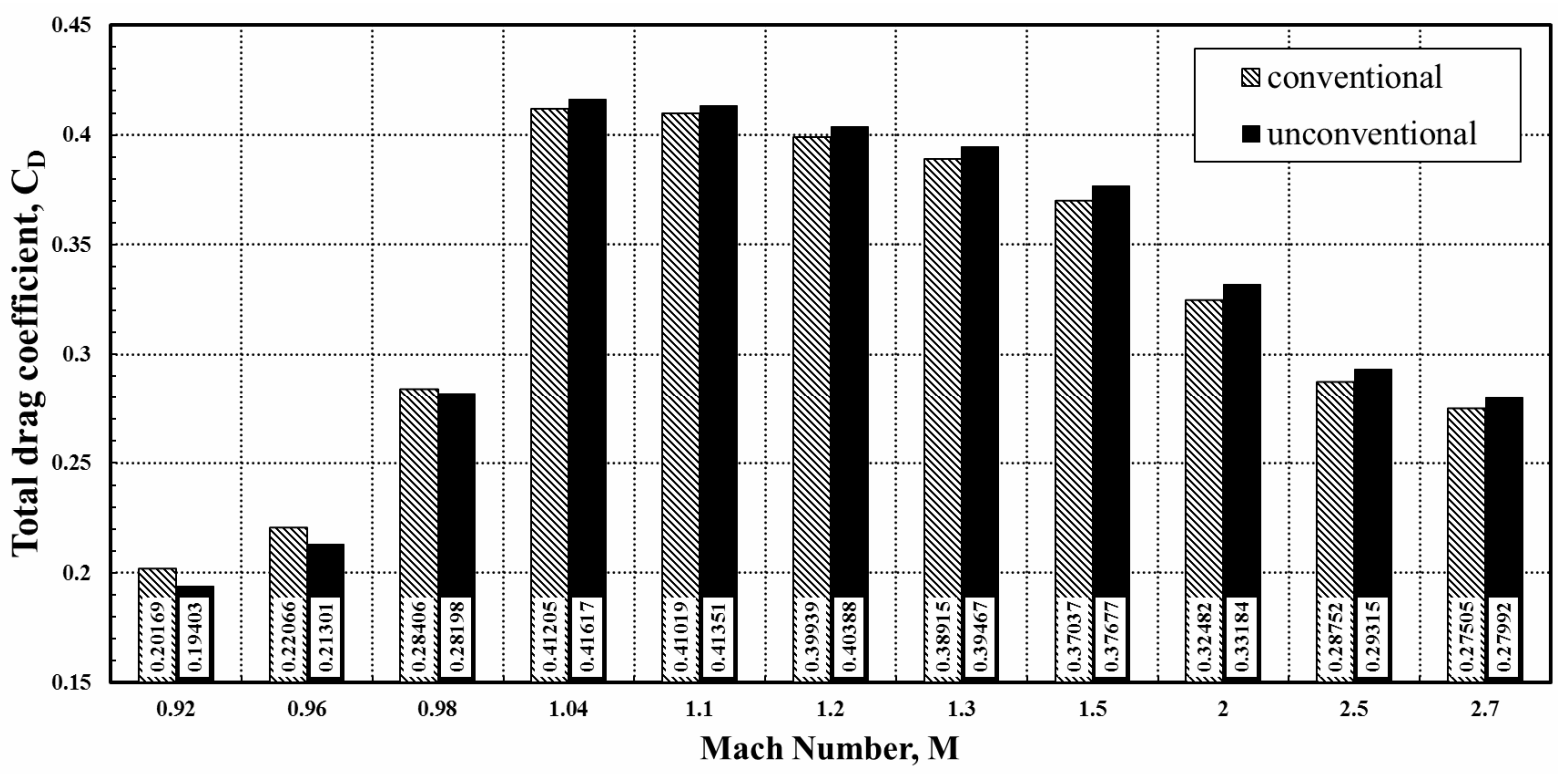

Fig. 7. Change of total drag coefficient with Mach number at zero incidence.

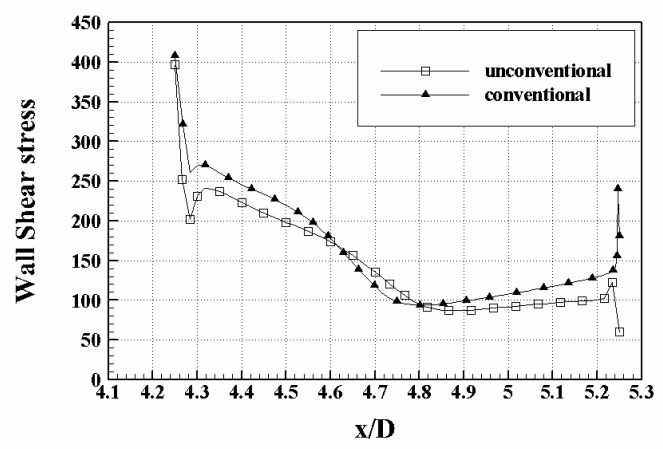

(a) $\mathrm{M}=0.96$

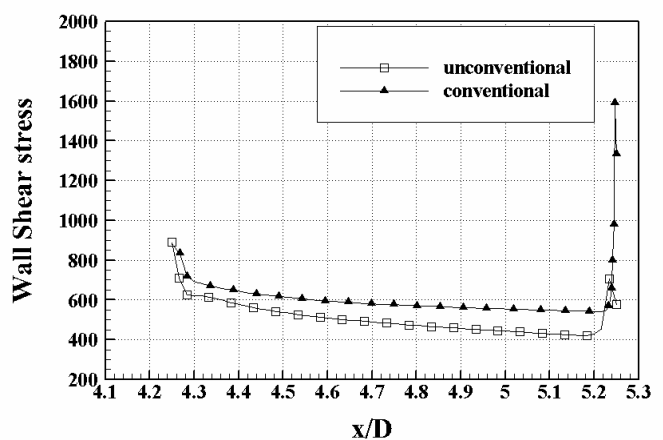

(c) $M=2.5$

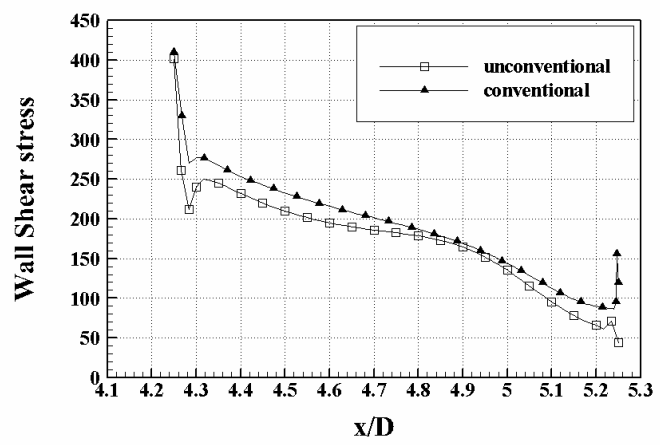

(b) $\mathrm{M}=0.98$

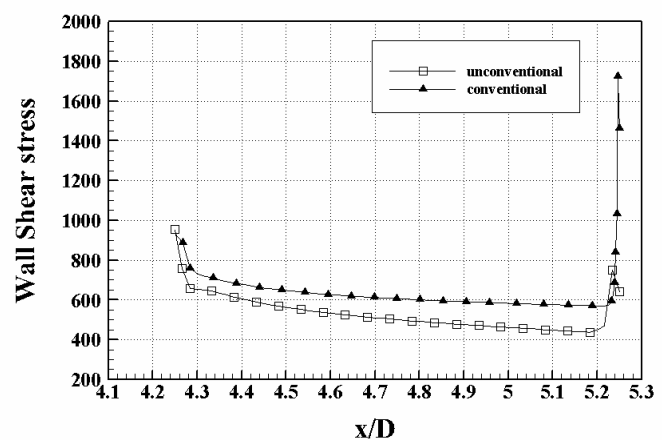

(d) $M=2.7$

Fig. 8. Wall shear stress at boattail surface.

perpendicular to the wall vanishes, i.e. the wall shear stress $\tau_{\mathrm{w}}$ vanishes. It can be seen from the figure that no flow separation occurred at the boattails for both cases. At Mach numbers 0.96 and 0.98 the drop of the wall shear stress - at $x / D$ equals to 4.6 and 5 respectively - is related to the existence of shock wave. In Fig. 8-a, the wall shear stress for the conventional model just before the shock wave is greater than 
that of the unconventional model. It can be noticed also that the gradient of the wall shear stress across the shock wave for the conventional model is higher than the unconventional one, which means that shock wave strength for the conventional model is higher. The wall shear stress is inversely proportional to the boundary layer thickness [12]. It can be deduced from Fig. 8 that at Mach numbers 0.98, 2.5 and 2.7 the wall shear stress reduces at downstream direction implying that the boundary layer is thickened, but at Mach number equals to 0.96 the wall shear stress decrease in the downstream direction until certain position then it increase again for both models.

Consequently, the base drag of the unconventional projectile is raised over the conventional one at supersonic speeds as shown in Fig. 9. It can be seen also that at transonic speeds the unconventional projectile has lower drag, taking into consideration that the two projectile models having almost same base area (conventional model is $2 \%$ higher). The two projectile models have the same trend for the base drag. For changing the Mach number from 0.92 to 0.98 , the base drag coefficient is decreases where the total drag coefficient increases in the same range, cf. Fig. 7. This may be related to the existence of the normal shock waves on the projectile body which cause another mechanism of drag which is the wave drag. The wave drag at these speeds is dominating the total drag.

Figure 10 shows the relation between the pitching moment coefficient $\mathrm{C}_{\mathrm{Ma}}$ about the center of gravity of each model and the Mach number for different projectile models. The center of gravity is located at 3.215D from the nose for unconventional projectile and 3.209 $\mathrm{D}$ for conventional projectile. The conventional projectile was simulated at angle of attack equals to three, where in the case of unconventional projectile the simulation was done at angle of attack of three and minus three. For all models, the predicted pitching moment is in the direction which increases the angle of attack. This means that it considers as instability moment.

The flat part of the unconventional projectile boattail is directed to the flow when the angle of attack is minus three and vice versa. Figure 10 shows that the flat surface formed in the boattail decreases the pitching moment coefficient which, in turn, increases the stability of the projectile.

The Mach contours at free stream Mach number equals to 0.98 can be shown in Fig. 11 for nonconventional projectile and Fig. 12 for conventional one. In case of the unconventional projectile model, the Mach contours are plotted at two planes. The first plane, Fig. 11-a, is passing through the median of flat part of the boattail, whereas the second plane, Fig. 11-b, is passing through the median of the conical part of the same model. For the conventional projectile model, the Mach contours are plotted at plane passing through the axis of the projectile. It can be seen in Fig. 11 that for unconventional projectile the shock wave on the flat part of the boattail is relatively smeared compared with the shock wave formed on the conical part and on unconventional projectile boattail may cause flow relaxation on the three flat surfaces [11]. These causes less wave drag compared with the conventional model at this Mach number. 


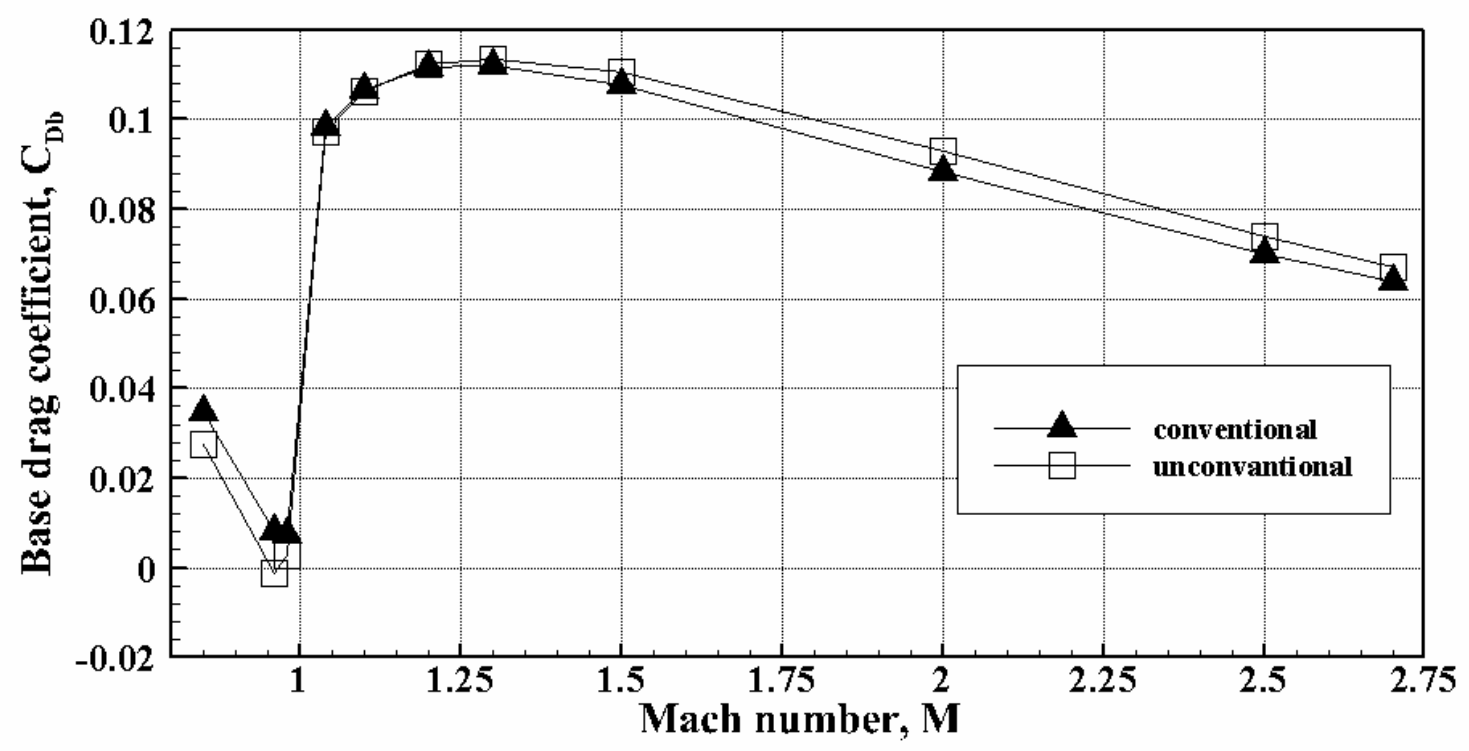

Fig. 9. Base drag coefficient $C_{D b}$ vs. the Mach number.

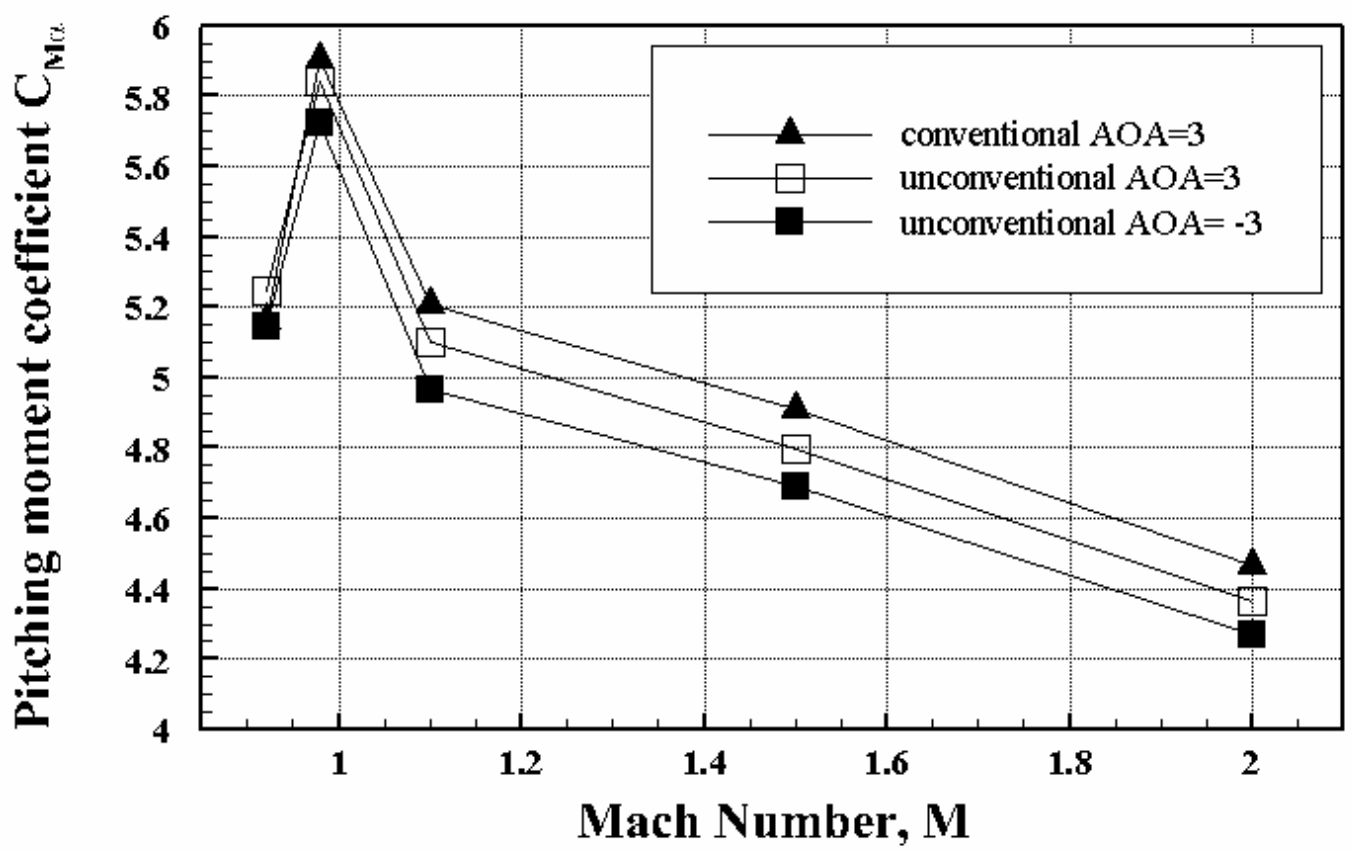

Fig. 10. Pitching moment coefficient vs. Mach number.

At the same mentioned planes Fig. 13 Shows the Mach contours over the unconventional projectile at free stream Mach number $M=2$. The Mach contours over the conventional projectile are shown in Fig. 14 at the same free stream Mach number. For each projectile model, a compression is formed over the shear layer downstream of the base resulting in the generation of an oblique shock wave behind the projectile base. For unconventional projectile, the flow over the flat surface, Fig. 13-a, was accelerated on the ten degrees inclination angle. This leads to a thinner and stronger oblique shock wave than that generated behind the conventional projectile base, cf. Fig. 14. 


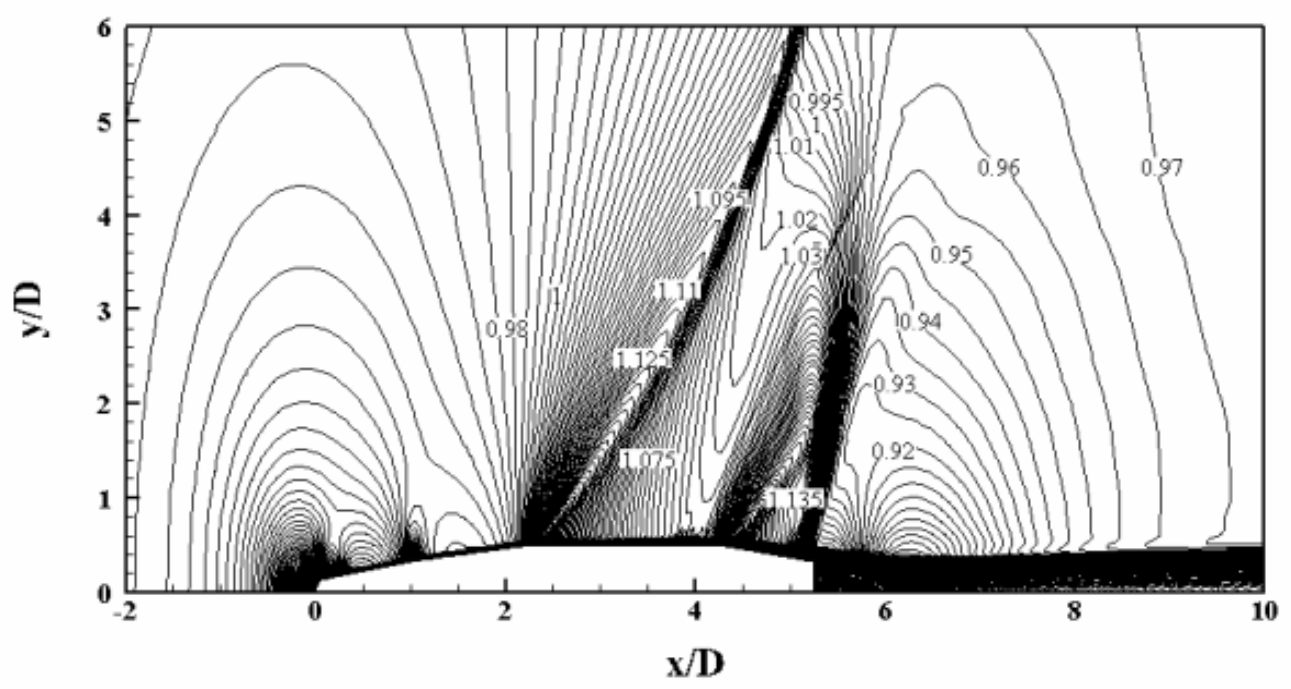

(a) Unconventional projectile flat side.

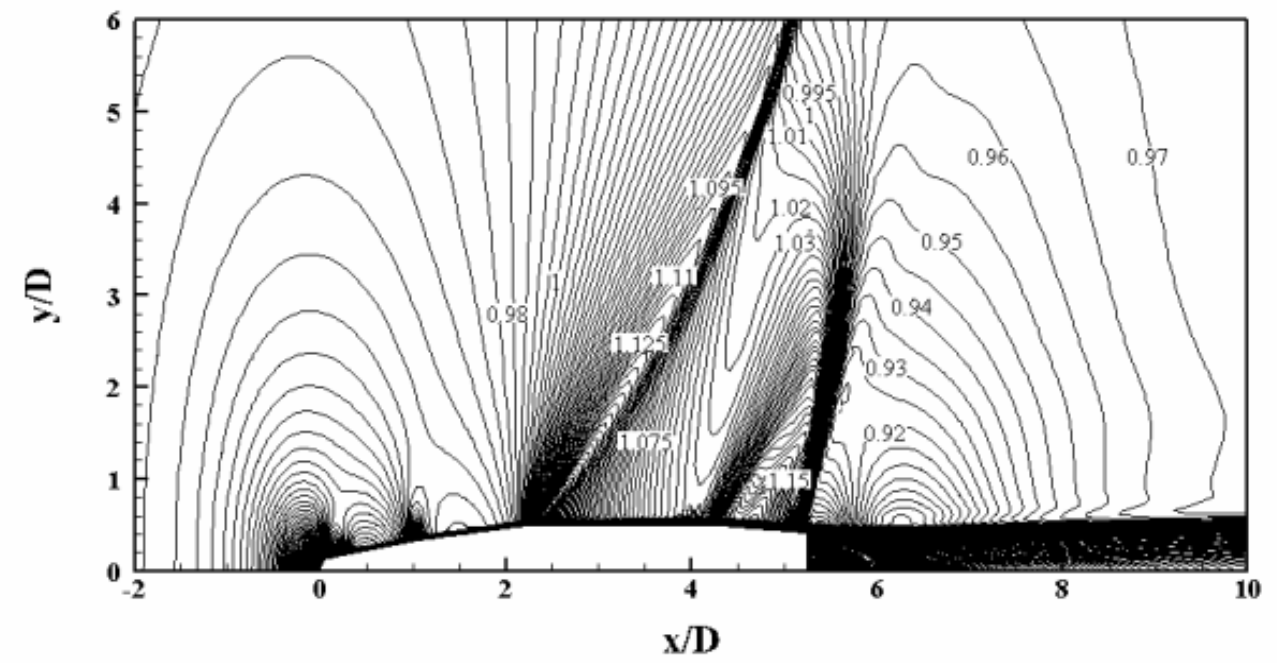

(b) Unconventional projectile cone side.

Fig. 11. Mach contours corresponding to free stream Mach number 0.98 for unconventional model.

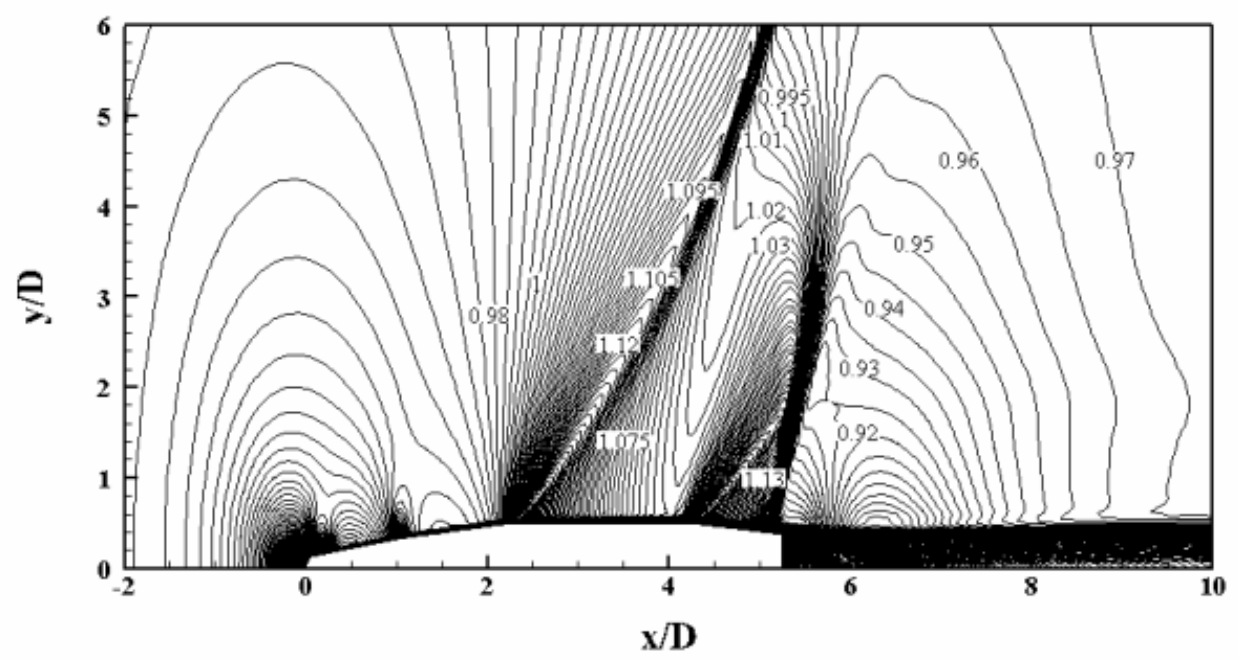

Fig. 12 Mach contours over conventional projectile at $M=0.98$. 


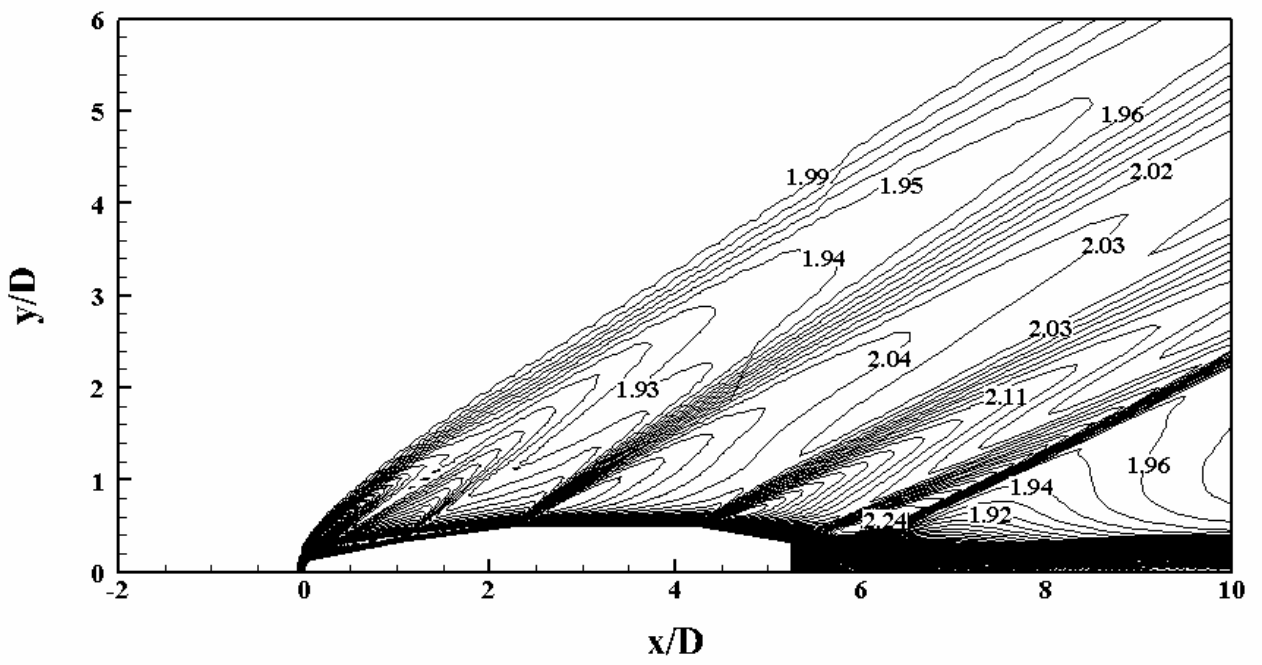

(a) Unconventional projectile flat side

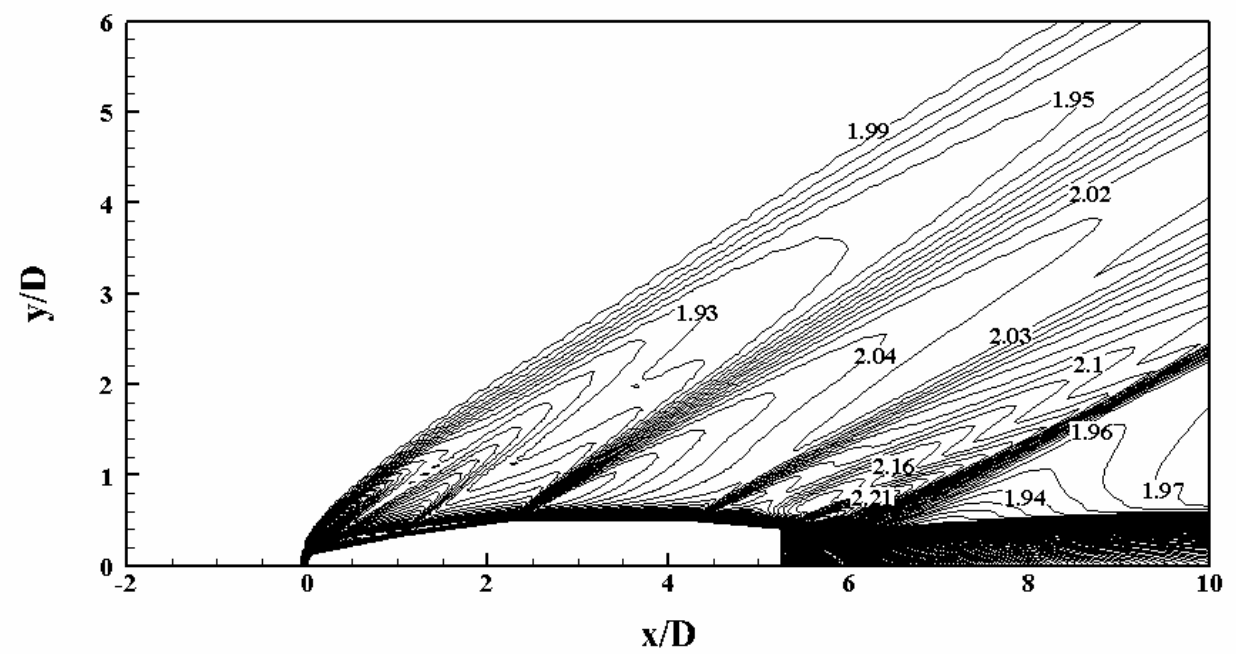

(b) Unconventional projectile cone side

Fig. 13. Mach contours corresponding to free stream Mach number 2 for unconventional model.

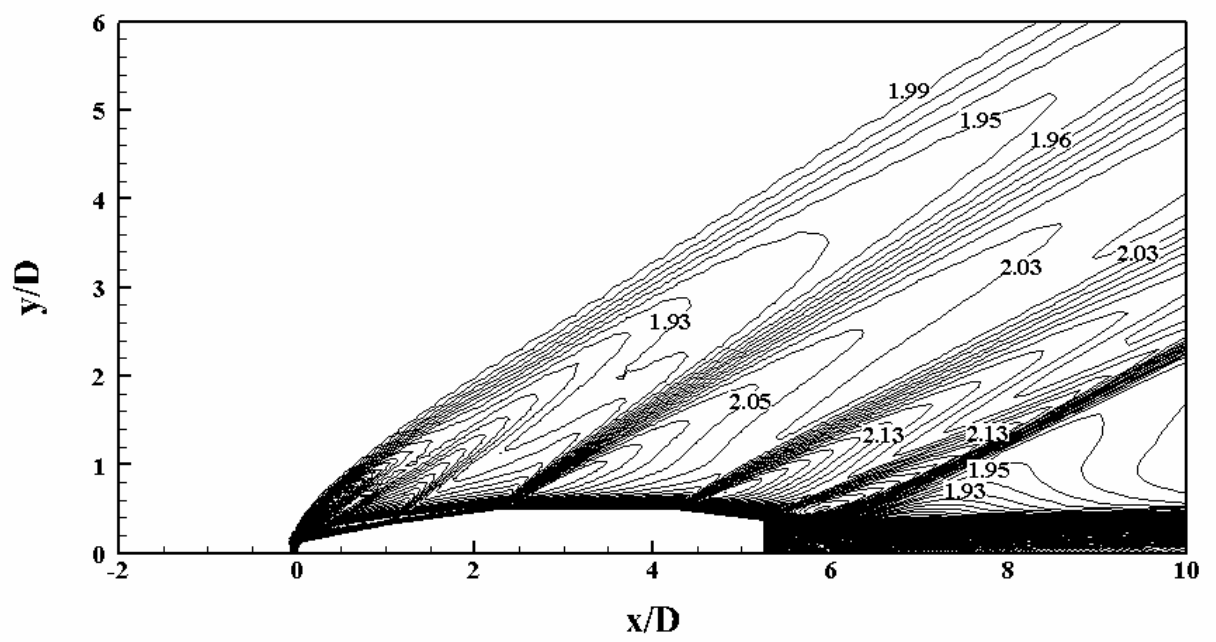

Fig. 14. Mach contours over conventional projectile at $\mathrm{M}=2$. 
Figure 15 illustrates the change of the position of the rear stagnation point with Mach number change for both projectiles, respectively. It can be seen that the stagnation point in the case of unconventional projectile is the closest to the projectile base for all free stream Mach numbers. For both models, the maximum value of the rear stagnation distance from the base is corresponding to Mach number equals to 1.04, this Mach number has also the largest total drag, cf. Fig. 7.

The streamlines in the base area were illustrated in the symmetry plane of the unconventional model and the conventional model; cf. Fig. 16 for different Mach numbers. The figures to the left correspond to unconventional projectile, whereas the figures to the right correspond to the conventional projectile. It can be seen that the rear stagnation point is corresponding to the wake size.

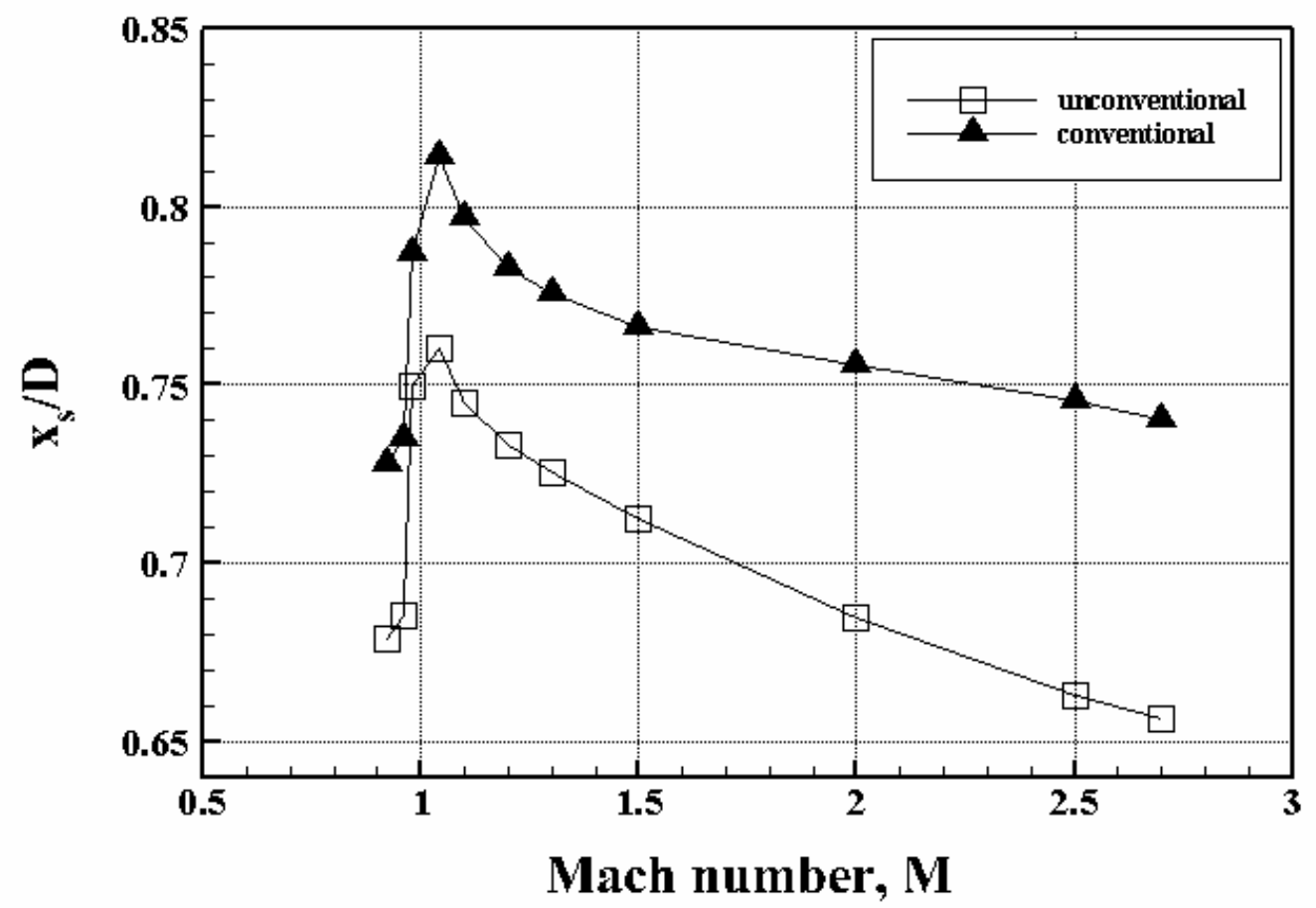

Fig. 15. Position of rear stagnation point vs. Mach number.

For unconventional model, the flat surface of the boattail is directed upward. The wake is not symmetric about the projectile axis; the vortex generated at the side of the flat surface of the boattail is larger than that at the conical side.

For conventional projectile, the wake is symmetric about the projectile axis. The wake shape and size was changed with the change of the Mach number. At supersonic speeds, the flow through the expansion wave at the base edge converges to the wake axis and the angle of the shock wave to the free stream decreases with the increase of the free stream Mach number. This result in convergence of the shear layer to the wake axis and changes the shape of the wake. This may make the rear stagnation point to move further towards the base as the free stream Mach number increases. 

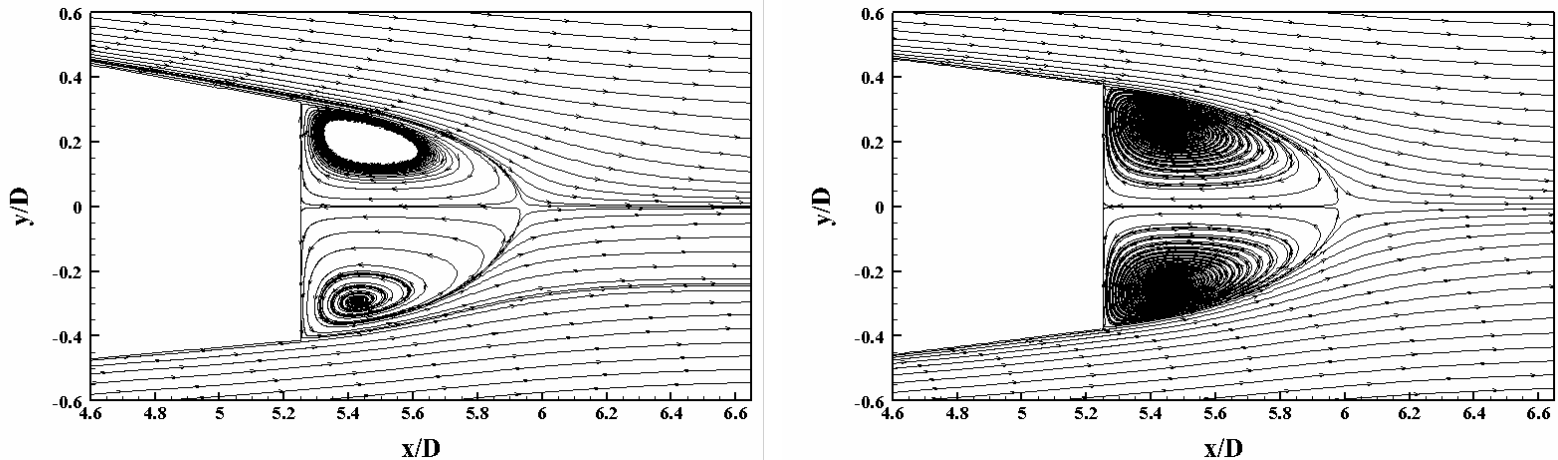

(a) $\mathrm{M}=0.96$
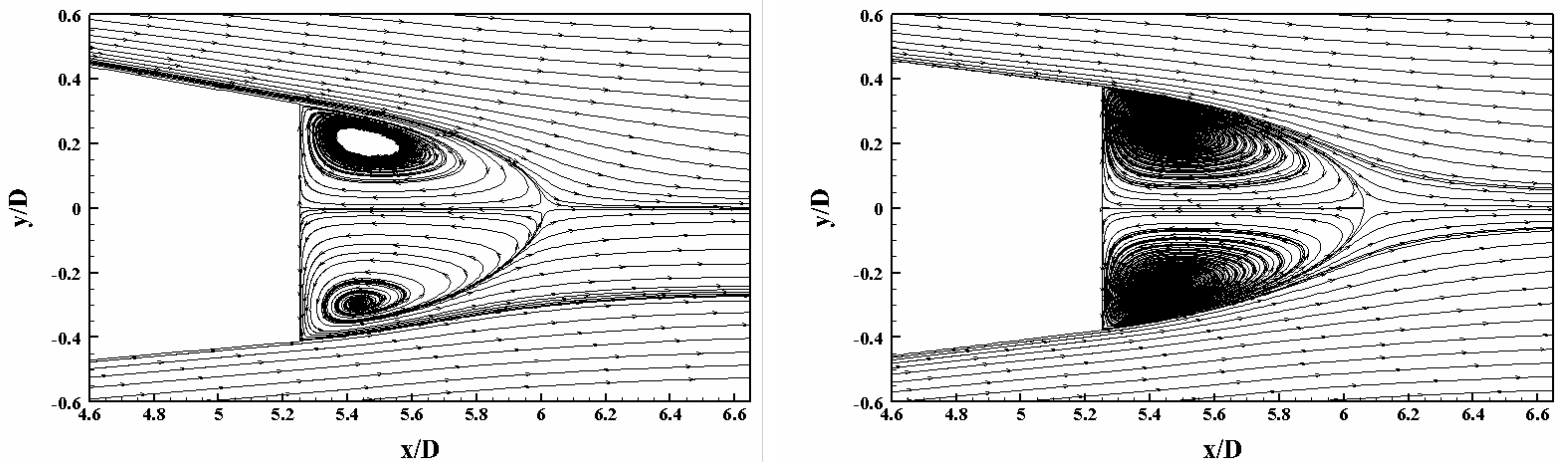

(b) $\mathrm{M}=1.04$
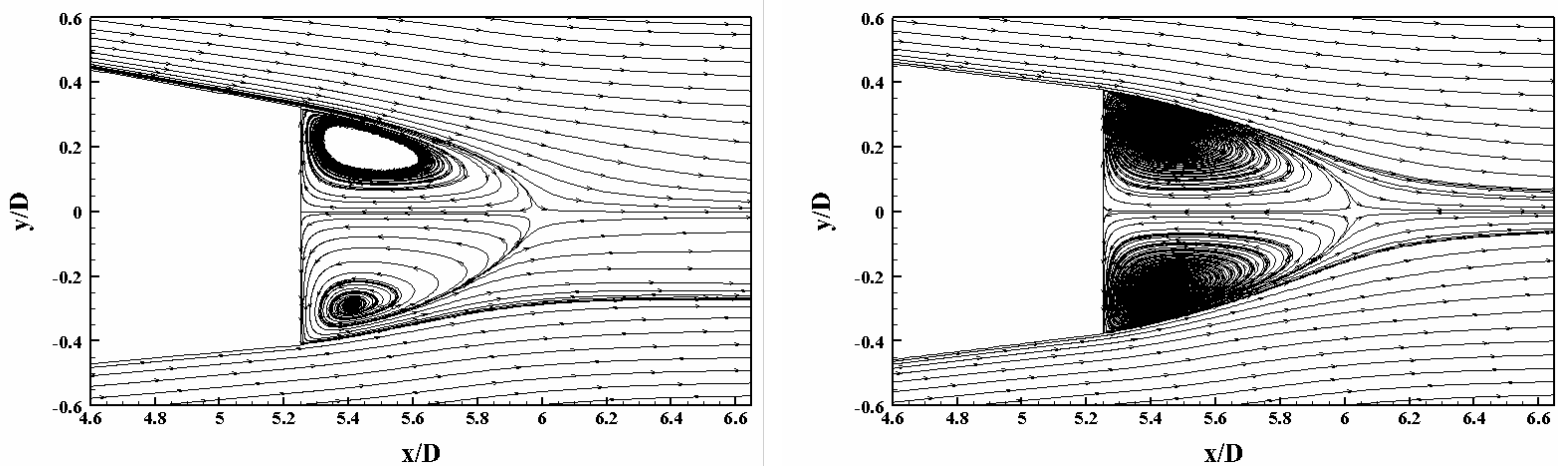

(c) $\mathrm{M}=1.3$
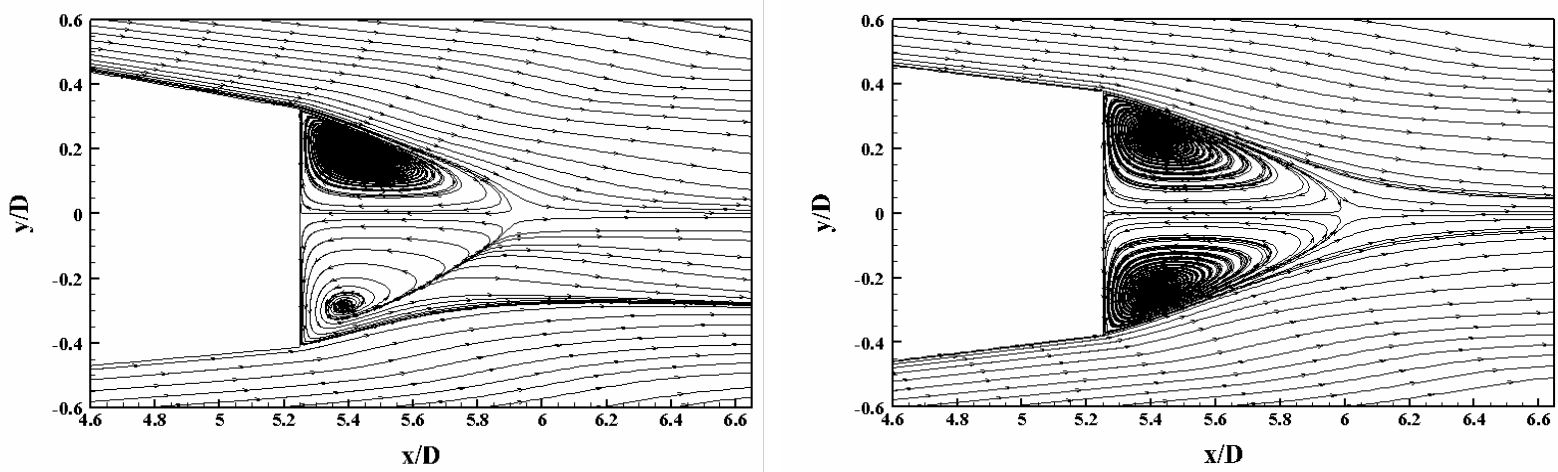

(d) $M=2.5$

unconventional model conventional model

Fig. 16. Streamlines past boattails of the two projectile models. 
The maximum range calculation was carried out using in-house code based on the point mass trajectory model. The muzzle velocity was set to $910 \mathrm{~m} / \mathrm{s}$, the projectile mass was equal to $488 \mathrm{~g}$ and the drag coefficients were as predicted from the simulations. The calculations were made at firing angles $10^{\circ}, 15^{\circ}, 30^{\circ}, 40^{\circ}$ and $50^{\circ}$. Fig. 17 shows the predicted change of range with firing angle for conventional and nonconventional projectiles. It can be seen that the conventional projectile has slightly longer range at all simulated firing angles. The extension in range has maximum value of $0.7 \%$ at firing angle $10^{\circ}$ and minimum value of $0.37 \%$ at firing angle $55^{\circ}$.

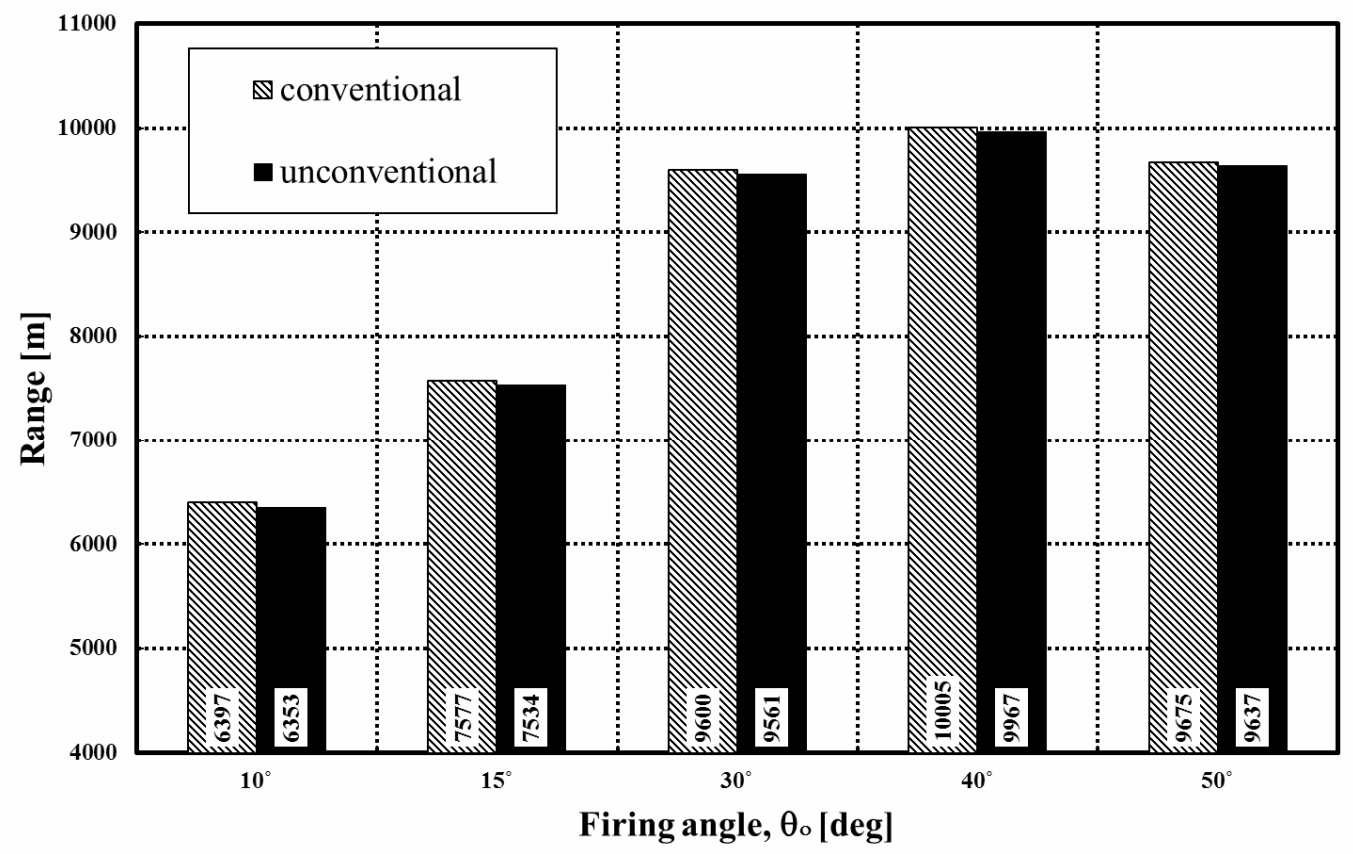

Fig. 17. Maximum range versus firing angle for all models.

\section{CONCLUSION}

The drag coefficient of the unconventional projectile model is lower than the drag coefficient of the conventional projectile model at transonic speeds, while at supersonic speeds the trend is reversed.

There is no flow separation at the boattail for the two projectile models. The rear stagnation point due to same free stream velocity is closer to the base in the case of unconventional projectile than that in case of the conventional projectile. The unconventional projectile has lower pitching moment coefficient than the conventional one which leads to relatively increasing the projectile stability during flight on its trajectory.

The trajectory calculation showed that for muzzle velocity equals to $910 \mathrm{~m} / \mathrm{s}$ and projectile mass of $488 \mathrm{~g}$, no advantage of the unconventional projectile model on the range. Also the conventional projectile doesn't have significant advantage on the trajectory over the unconventional model. 


\section{REFERENCES}

[1] Tanner, M., "Reduction of base drag", Progress in Aerospace Sciences, Vol. 16 No. 4: pp. 369-384. (1975).

[2] Fu, J.K. and S.M. Liang, "Drag Reduction for Turbulent Flow over a Projectile: Part I", J. Spacecraft and Rockets, Vol. 13,No. 1: pp. 85-92. (1994).

[3] Platou, A.S., "Improved Projectile Boattail", J. Spacecraft and Rockets, Vol. 12,No. 12: pp. 727-732. (1975).

[4] Liang, S.-M. and J.-K. Fu, "Passive Control Method for Drag Reduction for Transonic Projectiles", in 9th AIAA Applied Aerodynamics Conference: Baltimore, MD. (1991).

[5] Kayser, L.D. and W.B. Sturek, "Aerodynamic Performance of Projectiles with Axisymmetric and Non-axisymetric Boattails", ARBRL-MR-03022, US Army Ballistic Research Laboratory, (1980).

[6] Stahara, S.S., J.P. Elliott, and J.R. Spreiter, "Transonic Flow Past Various Boattail Projectiles: Equivalence Rule Analysis", in AIAA 19th Aerospace Sciences Meeting, AIAA: St. Louis, Missouri. (1981).

[7] Stahara, S.S., J.P. Elliott, and J.R. Spreiter, "Transonic Flow Past Axisymmetric and Nonaxisymmetric Boattail Projectiles", AIAA Journal, Vol. 20,No. 10: pp. 1329-1337. (1982).

[8] Guidos, B.J. and W.B. Sturek, "Computational aerodynamic analysis for the design of a spinning non-axisymmetric shell", in Applied Aerodynamics Conference, 4th: San Diego, CA. pp. 368-381. (1986).

[9] Agnone, A.M. and B. Prakasam, "Hypersonic Aerodynamics of Nonaxisymmetric Boattailed Bodies", J. Spacecraft and Rockets, Vol. 24,No. 6: pp. 181-182. (1987).

[10] Spalart, P.R. and S.R. Allmaras, "A One-Equation Turbulence Model for Aerodynamic Flows", in 30th Aerospace Sciences Meeting and Exhibit, AIAA: Reno, NV. (1992).

[11] El-Awwad, E., et al., "Numerical Study on Flow Characteristics of Air Past a Projectile with a triangular Base", to be published in 15th International Conference on Applied Mechanics and Mechanical Engineering, Military Technical College: Cairo, Egypt. (29-31 May 2012).

[12] Schlichting, H. and K. Gersten, "Boundary Layer Theory". 8th Edition ed: Springer. (2000). 


\section{APPENDIX A:}

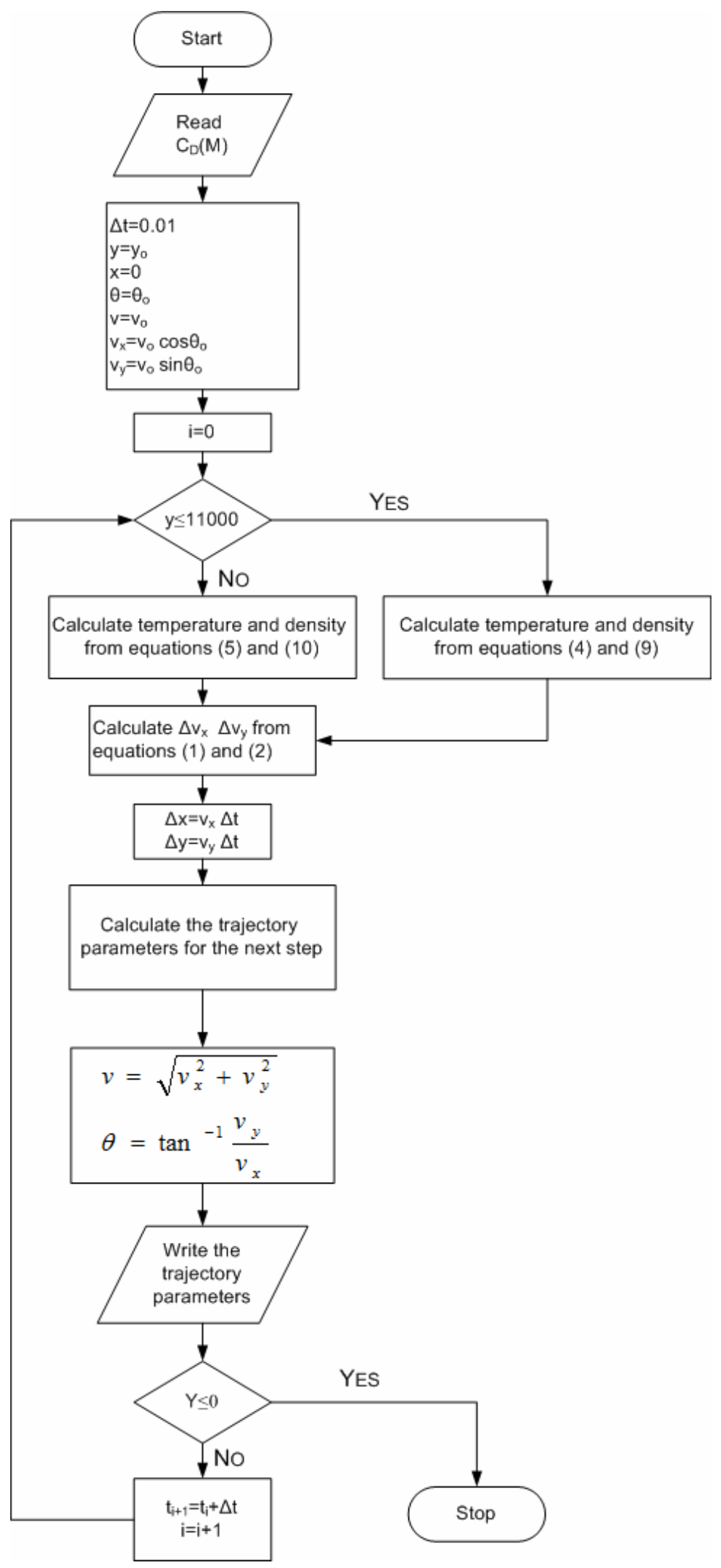

Fig. A1 trajectory parameters calculation flow chart. 